\title{
ENIGMAS DA APARÊNCIA: A FUNÇÃO DO FENÔMENO ORIGINÁRIO PARA A CRÍTICA SOCIAL DE WALTER BENJAMIN
}

\author{
Abrahão Antônio Braga Sampaio ${ }^{1}$
}

\begin{abstract}
Signos arbitrários, letras e o quer que seja não substituem o fenômeno. [...] Aqui se trata propriamente de fenômenos que devem se tornar presentes à visão do corpo e do espírito, a fim de se poder reconstruir com clareza, para si e para os outros, sua origem e desenvolvimento.
\end{abstract}

Goethe, A Doutrina das cores.

\section{RESUMO}

As bases para uma crítica sócio-cultural nos marcos de uma historiografia materialista constituem o cerne do projeto das Passagens (1927-1940) de Walter Benjamin (1892-1940). Tal projeto mantém sua especificidade, no âmbito da crítica marxista, por configurar um desdobramento do conceito "clássico" de caráter fetiche da mercadoria. Porém, com base na noção de imagem. Trata-se de aclarar a conexão expressiva entre economia e cultura como condição necessária para o desdobramento do fetiche nas fantasmagorias culturais na visibilidade dos fatos econômicos e conferir seu conteúdo imagético enquanto espaço simbólico. Benjamin constata a transformação da mercadoria em fantasmagoria na extensão da aparência social. Porém, os lineamentos desse procedimento teórico-conceitual da obra tardia de Benjamin podem ser rastreados já nos escritos de juventude. Com base nesta hipótese, o problema da constituição da categoria de aparência será abordado com intuito de averiguar como se integram componentes estéticos ao quadro da crítica social benjaminiana, ou seja, como estão vinculados os aspectos estéticos e sociais na elaboração do método dialético, decisivo para crítica posterior da aparência mítica. Nesse contexto, evidencia-se o papel da transposição teórica do conceito de fenômeno originário do plano do pensamento morfológico de Goethe (1749-1832) para o plano da história efetuada por Benjamin, bem como sua teoria da verdade enquanto transitoriedade apropriada da crítica de arte dos primeiros românticos.

Palavras-chave: Aparência. Crítica. Fenômeno Originário. Transposição. Passagens.

É constante a reflexão de Walter Benjamin, durante todo seu percurso intelectual, sobre as questões e inter-relacionamentos entre a aparência (Schein), a linguagem e o plano da história. As pesquisas de Benjamin desde os seus primeiros trabalhos sobre filosofia da linguagem, eminentemente de caráter teológico, do período de juventude até a maturidade de suas análises materialistas não perdem

1 Abrahão Antônio Braga Sampaio é doutorando em Filosofia na UFC (Universidade Federal do Ceará. 
jamais de vista o aspecto de reflexão em torno da vida histórica. Com isso, não se pode evidenciar propriamente fases de ruptura radical na produção do autor, mas de reestruturação de suas convicções teóricas basilares a respeito de um pensamento dialético na concepção de um senso crítico da história. $O$ aspecto mais relevante dessa postura centra-se na teoria benjaminiana da verdade, apreendida na necessidade de uma linguagem que exponha e apreenda o caráter de transitoriedade da história, mas também se opondo às filosofias do sujeito e da representação mental. Assim, todas as questões, tanto estéticas quanto linguísticas ou culturais, estariam amplamente assentadas sobre uma concepção dialética do tempo histórico.

O projeto sobre as passagens parisienses se firmaria como a consumação dos textos de juventude ${ }^{2}$ na tentativa de articular as dimensões da linguagem, da aparência e da vida histórica na constituição de uma historiografia materialista que se contrapõe a qualquer proposta de interpretação do mundo que se paute, em última instância, no atemporal ou na naturalização dos produtos da história. Tampouco Benjamin está interessado na imagem de uma futura reconciliação, de um topos harmônico e abstrato de uma humanidade redimida. Estes tipos de interpretação são imediatamente o 'contrário' da vida histórica dos homens e se caracterizam como dissolução da história no terreno do mito ${ }^{3}$. Com propósito

${ }^{2}$ O exemplo mais característico da coerência das reformulações do pensamento de Benjamin é a tematização da analogia entre alegoria e mercadoria na poesia de Baudelaire. $\mathrm{Na}$ investigação sobre a situação da obra de de arte na modernidade encontra-se o ponto de unidade no pensamento bejaminiano. Segundo Gilloch: "Il 'completamento' dell'opera d'arte avviene paradossalmente nel della sua estinzione. La critica immanente qui diviene la rovina o la 'mortificazione' dell'opera d'arte: intuizione fondamentale, questa, che costituirà la base tanto dello studio sul Trauerspiel quanto della Passagenarbeit' (GILLOCH, Graene. Walter Benjamin. Trad. it. Stefano Manfredi. Bologna: il Mulino, 2008, p. 58). Sobre tal problemática em Baudelaire, o autor acrescenta: "Se la Passagenarbeit doveva esplorare il XIX secolo così come lo studio sul Trauerspiel aveva iluminato il XVII, allora Baudelaire, inteso come allegorista, rappresentava un essenziale punto di continuità tra i due progetti, un sole in ogni costellazione. (...) Per Benjamin c'era un'affinità speciale tra la forma della merce e l'allegoria, un'affinità centrale sia per la sua concezione di Baudelaire sia per il lavoro critico redentivo de 'progetto dei passages'"(p.289). Cf. também AGAMBEN, Giorgio. "Langue e histoire: Catégories historiques et catégories linguistiques dans la pensée de Benjamin" In WISMANN, Heinz. (organizador). Walter Benjamin et Paris, pp.793807. Paris: Les èdition du Cerf, 1986.

3 O sentido dessa postura que diferencia mito e história, perene na obra de Benjamin, encontra-se expressa de maneira clara já em seus primeiros textos, como na abertura de um discurso pronunciado em 1915 intitulado $A$ vida dos estudantes: "Há uma concepção de história que, confiando na eternidade do tempo, só distingue o ritmo dos homens e das épocas que rápida ou lentamente correm na esteira do progresso. A isso corresponde a ausência de nexo, a falta de precisão e de rigor na exigência que ela coloca em relação ao presente. A consideração que se segue visa, porém, um estado determinado, no qual a história se encontra repousada em um foco, tal como desde sempre nas imagens utópicas dos pensadores. Os elementos do estado final não estão manifestos como tendência amorfa do progresso, mas encontram-se profundamente 
explícito de articular uma crítica social com base na interpretação dos fenômenos da aparência social cotidiana do capitalismo moderno e seus elementos estéticos na Paris, capital do século XIX, o projeto das Passagens coloca claramente, portanto, o problema de uma categorização teórica da aparência em dois planos diversos: o social e o estético ${ }^{4}$; ao mesmo tempo o projeto representa um adensamento teórico da perspectiva emancipatória do pensamento de Walter Benjamin de inspiração marxista.

O quadro metodológico, até onde foi possível ser desenvolvido, do trabalho inconcluso do autor alemão tem por desiderato estabelecer quais os tipos de interação e conexão existentes entre economia e cultura. A categoria social da reificação, pedra angular da interpretação das relações econômicas fetichistas, é conjugada a uma retomada da reflexão sobre a aparência estética nos marcos da constituição de uma teoria crítica da arte. Benjamin preconiza a transposição de uma série de categorias (não imediatamente concernentes à vida social e histórica) para o plano da história, entre elas a categoria estética de aparência ${ }^{5}$. Daí, surgir

engastados em todo presente como as criações e os pensamentos mais ameaçados, difamados e desprezados. Transformar o estado imanente da plenitude de forma pura em estado absoluto, torná-lo visível e soberano no presente, eis a tarefa histórica. Contudo, esse estado não pode ser expresso através da descrição pragmática de pormenores, da qual ele antes se furta, mas só pode ser compreendido em sua estrutura metafísica, como o reino messiânico ou a idéia da Revolução Francesa" (In: BENJAMIN, Walter. Reflexões:a criança, o brinquedo, a educação. Trad. br. de Marcus Mazzari. São Paulo: Summus, 1984. p.31).

${ }^{4}$ Cf. AQUINO, J. E. Walter Benjamin e a aparência social no capitalismo in COUTO, Edvaldo Souza; DAMIÃO, Carla Milani (Organizadores). Walter Benjamin, Formas de percepção de estética da modernidade. Salvador: Quarteto, 2008, pp. 207-224. Cf. também STEINER, Uwe. "Zarte Empirie: Überlegungen zum Verhältnis von Ursprung in Früh- und Spätwerk Walter Benjanins", pp. 20-40 in: BLOZ, Nobert W.; FABER, Richard (organizadores) Antike und moderne: zu Walter Benjanins Passagen. Würzburg: Königshausen und Neumann, 1986.

${ }^{5}$ Esta é uma questão decisiva para o estilo filosófico benjaminiano, acentuada no seu trabalho de maturidade: a maioria das categorias metodológicas elaboradas são provenientes de quadros teóricos bastantes diversos e exteriores ao marxismo. Tal procedimento, notadamente na produção tardia do filósofo, faz parte de um processo complexo de refundição conceitual, o qual não representa mero ecleticismo. Sobre tal questão pode-se dar alguns exemplos, além da noção de fenômeno originário: a maneira como Benjamin rejeita uma explicação de cunho causal e determinista na interação entre economia e cultura pela introdução preliminar da categoria de expressão, cuja posição resulta em uma ampliação da teoria marxista da superestrutura. Nesse momento, é suficiente apenas frisar que, para o autor alemão, a experiência do uso coletivo das forças produtivas no âmbito de alargamento das relações fetichistas estrutura-se no "modelo do sonho". Analogamente à experiência do indivíduo que sonha, as produções culturais se constituem numa conexão expressiva com a base econômica gerando assim um espaço simbólico. Os desafios epistemológicos lançados pela psicanálise para a elaboração do sentido do trabalho do sonho e sua respectiva interpretação também são transpostos por Benjamin para o plano histórico - algo já ensaiado pelos surrealistas Louis Aragon(1897-1982) e André Breton(1896-1966) - na exposição da relação entre os fenômenos da cultura do fetiche da mercadoria na vida espiritual do século XIX e a sua base econômica pela integração da psicanálise freudiana. Conforme Susan BUCK-Morss, levando o processo de refundição conceitual proposta por Benjamim: "A teoria mistura elementos do surrealismo e de Proust, de Marx e de Freud, com traços de gerações 
inevitavelmente uma série de problemas: primeiramente, como articular uma crítica sem incorrer no risco de uma estetização da aparência social; em segundo lugar, se essa transposição é efetivamente possível; e, em terceiro lugar, como essa transposição pode se ancorar na categoria social da reificação. Aqui, não se trata propriamente do problema da legitimidade da transposição teórica, mas de assegurar os lineamentos do quadro metodológico desenvolvido por Benjamin e a articulação do seu pensamento por meio de apropriações teóricas de caráter eminentemente analógico. Dessa maneira, o ponto de contato entre a reflexão estética e a teoria social é concebido na relação entre crítica de arte e a constituição de uma aparência estética criticável, bem como na exposição do plano de uma crítica do mito ou, mais apropriadamente, de uma crítica imanente da aparência mítica.

Pode-se abrir campo inicialmente para o entendimento da categoria de aparência na obra de Benjamin partindo de sua tese doutoral intitulada $O$ Conceito de crítica de arte no romantismo alemão (1919). Mais especificamente, na ultima seção ${ }^{6}$, que trata da diferença das concepções de arte nos primeiros românticos e em Goethe. Com base no confronto entre estas filosofias da arte opostas em seus princípios, no âmbito da relação estética entre forma e conteúdo em vistas da criticabilidade das obras de arte, Benjamin propõe a noção de uma aparência estética criticável ${ }^{7}$. Em primeiro lugar, os românticos alemães compreendiam a obra de arte enquanto Ideia, ou seja, ela se desenrola em um processo de reflexão infinita do continuum das formas. Para Novalis e F. Schlegel, por exemplo, a crítica tem o papel de dar continuidade às obras, de forjar o seu acabamento em uma reiteração constante - no médium-de-reflexão - de novas formas sem nunca estar sob a égide de um modelo canônico de arte, tal crítica se constitui no a priori da forma. Essa concepção primeiro romântica é caracterizada por Benjamin da seguinte maneira:

históricas e de cognição infantil, em uma combinação unida mais por meios literários que lógicos. No entanto, a qualidade da experiência histórica que Benjamin tentava captar em sua montagem teórica se transmite como resultado vital para esse projeto" (BUCK-MORSS, Susan. Dilalética do olhar: Walter Benjamin e o projeto das Passagens, p.302).

6 BENJAMIN, Walter. O Conceito de crítica de arte no romantismo alemão. Trad. br. de Marcio Seligmann-Silva. São Paulo: Iluminuras, 1993, pp. 114-123.

7 Benjamin limita-se a apresentar o problema na tese doutoral, seu significado mais amplo será alcançado no em outro trabalho de juventude: As Afinidades eletivas de Goethe de 1922. No espaço desta pequena apresentação não seria possível uma análise da referida obra, apropriada para uma investigação de maior fôlego. Para tanto cf. CASTRO, Cláudia. A Alquimia da crítica: Benjamin e as afinidades eletivas de Goethe. Rio de Janeiro: Paz e Terra, 2011. 
A obra de arte não pode ser um torso. Deve ser um momento em movimento e transitório na forma transcendental vivente. Na medida em que ela se limita em sua forma, se faz transitória em uma configuração casual, numa configuração passageira torna-se, no entanto, eterna, via crítica./Os românticos queriam tornar absoluta a regularidade da obra de arte. Mas é apenas com a dissolução da obra de arte que o momento do casual pode ser dissolvido ou, antes, transformado numa regularidade ${ }^{8}$.

Daí surge a polêmica radical desses autores com a doutrina da arte de Goethe, que celebriza a produção artística grega como cânon para o artista. Diferentemente dos primeiros românticos, Goethe relaciona o fenômeno artístico ao Ideal, o qual se distingue por seu teor (Gehalt) e pelo seu conteúdo (Inhalt). Nesse sentido, a obra de arte seria marcada pela presença indireta do ideal em sua configuração sensível e concreta, pela refração do ideal na obra, cujo conteúdo pode se oferecer precariamente através da intuição dos arquétipos (Urbilder), estes jamais sendo propriamente ou diretamente percebidos, pois seu conteúdo é a ideia da natureza a qual as obras de arte devem se assemelhar. Os arquétipos permanecem "eleaticamente imóveis", tais como a ideia no sentido que Benjamin atribui na sua leitura de Platão ${ }^{9}$. A obra de arte assim concebida encerra, portanto, um paradoxo constitutivo: elas têm que se fazerem perceptíveis, no entanto, não são cópias dos arquétipos, mas apenas a eles se assemelham enquanto propiciam uma percepção refratária e descontínua do ideal. Na teoria goetheana da aparência estética, com base no a priori do teor, a crítica de arte fica inviabilizada, pois, sem padrão crítico, a aparência harmoniza-se consigo mesma. A ideia da natureza torna-se, nesse caso, apenas intuível.

8 BENJAMIN, Walter. O Conceito de crítica de arte no romantismo alemão, p. 119.

9 A adoção de Platão por parte de Benjamin não significa uma retomada da ontologia realista hierárquica que cinde o mundo fenomênico das formas supra-sensíveis e primeiras, mas um questionamento da fragilidade da linguagem no tocante à apreensão conceitual dos fenômenos. Nesse sentido, a "verdade" é imanente ao sensível e à transitoriedade temporal e relaciona, na realidade do mundo, a relação mútua entre beleza e verdade. Esta leitura benjaminiana ousada de Platão, do Banquete especificamente, é sintetizada com precisão por J. M. Gagnebin: "Não só a beleza é redimida de sua tendência a somente pertencer ao domínio do brilho (Schein) e da aparência (Erscheinung, Schein) pela sua última ligação à verdade; também esta, a verdade, precisa por assim dizer, da beleza para ser verdadeira: a verdade não pode realmente existir sem se apresentar, se mostrar e, portanto, aparecer na história e na linguagem. Não há, então, subsunção da beleza à verdade em uma hierarquia ontológica que submete o sensível ao inteligível e o aparecer ao ser. Entre verdade e beleza haveria uma relação de co-pertencimento constitutivo como entre essência e forma: como forma da verdade, a beleza não pode se contentar em brilhar e aparecer, se quiser ser fiel à sua essência, à verdade; e, reciprocamente, como essência da beleza, a verdade não pode ser uma abstração inteligível "em si", sob pena de desaparecer, de perder sua Wirklichkeit (realidade efetiva)" (In: GAGNEBIN, Jeane-Marie. Do Conceito de Darstellung em Walter Benjamin ou Verdade e Beleza in Kriterion vol.46 no.112 Belo Horizonte Dec. 2005, p. 190) 
É exatamente nesse paradoxo que se torna inteligível o conceito goetheano de fenômeno originário ou fenômeno primordial (Urphänomen $)^{10}$, que faz a mediação entre a filosofia da arte do poeta alemão e suas especulações sobre a natureza, bem como a posterior apropriação crítica dessa categoria por Benjamin. Desse modo é preciso salientar:

\begin{abstract}
Abarcar a idéia da natureza e, deste modo, torná-la apta para ser arquétipo da arte (para ser puro conteúdo), este era, em última análise, o esforço de Goethe em sua averiguação dos fenômenos originários. A proposição, a obra de arte imita a natureza, pode portanto ser correta num sentido mais profundo, desde que se compreenda como conteúdo da obra de arte a natureza mesma e não a verdade natura $\left.\right|^{11}$.
\end{abstract}

Assim, somente na arte a natureza verdadeira intuível estaria presente, imageticamente visível, sob o estatuto de fenômeno originário, ao passo que na natureza visível, propriamente natural, ela estaria presente, mas escondida e dissolvida em meras aparições. Nesse ponto, com base em uma leitura desviada e apropriação crítica, opera-se a distinção conceitual de Benjamin em relação a Goethe. $O$ uso das categorias goetheanas para a concepção de crítica apenas é possível se a ideia da natureza não for apreendida imediatamente como natureza do mundo, aparente e sensível - mais uma vez eis a leitura benjaminiana de Platão presente. A aparência sensível verdadeira agrega a si mesma o fenômeno originário, que the permite distingui-la de qualquer outra aparência sensível. De fato, a apropriação benjaminiana do fenômeno originário extrai, contrariamente às intenções de Goethe, a possibilidade da crítica imanente das obras de arte ao mesmo tempo em que forja uma noção de aparência que the corresponda, ou seja, como categoria que possui na criticabilidade seu elemento constitutivo.

Em Origem do drama barroco alemão (1925), o conceito de fenômeno originário surge metamorfoseado na noção de origem (Ursprung), a qual se diferencia prontamente da noção de gênese ou proveniência. Como assinala Benjamin, a origem não se destaca dos fatos históricos ao passo que também não pode ser compreendida em aspectos meramente cronológicos, mas sim enquanto aquilo que não se destaca da pré e pós-história do fenômeno, em um processo de destruição que configura, ao mesmo tempo, a sua redenção platônica. Benjamin

\footnotetext{
${ }^{10}$ Cf. MACHADO, Francisco de Ambrosis Pinheiro. Imanência e História: a crítica do conhecimento em Walter Benjamin. Belo Horizonte: editora UFMG, 2004, pp. 94-99; e TIEDEMANN, Rolf. Études sur la philosophie de Walter Benjamin. Trad. de Reiner Rochlitz. Actes Sud, 1987, pp. 81-92.

${ }^{11}$ BENJAMIN, Walter. O Conceito de crítica de arte no romantismo alemão, p.116.
} 
apresenta essa concepção no famoso "Prefácio", visando esclarecer o procedimento teórico elaborado em sua obra:

\begin{abstract}
O termo origem não designa o vir-a-ser daquilo que se origina, e sim algo que emerge do vir-a-ser e da extinção. A origem se localiza no fluxo do vira-ser como um torvelinho, e arrasta em sua corrente o material produzido pela gênese. $O$ originário não se encontra nunca no mundo dos fatos brutos e manifestos, e seu ritmo só se revela a uma visão dupla, que o reconhece, por um lado, como restauração e reprodução, e por outro lado, e por isso mesmo, como incompleto e inacabado. Em cada fenômeno de origem se determina a forma com a qual uma idéia se confronta com o mundo histórico, até que ela atinja sua plenitude na totalidade de sua história. A origem, portanto, não se destaca dos fatos, mas se relaciona com sua pré e pós-história ${ }^{12}$.
\end{abstract}

Desse modo, o fenômeno originário seria a intuição do não-perceptível e da forma inteligível dos e nos fenômenos visíveis. Como ideia da natureza, tal forma é imanente à coisa e configuradora dos fenômenos perceptíveis. Goethe em sua Doutrina das cores (1804) aborda o conceito de fenômeno primordial, exemplificado no esboço da constituição do fenômeno cromático, como captação dos fenômenos concretos em escala progressiva, cuja totalidade emerge como percepção simultânea que não pode ser conservada ${ }^{13}$. Assim, conforme a postura antimetafísica de Goethe:

\begin{abstract}
Expressar a essência de algo é propriamente um empreendimento inútil. Percebemos efeitos, e uma história completa destes bem poderia abranger a essência daquele. Em vão nos esforçamos por descrever o caráter de uma pessoa, mas basta reunir suas ações e feitos para que uma imagem do seu caráter nos seja revelada ${ }^{14}$.
\end{abstract}

Os fenômenos originários articulam-se como a união de opostos nos fenômenos aparentes particulares ${ }^{15}$ em uma polaridade primordial imanente, pois, nas palavras de Goethe, "tudo o que aparece, tudo que se manifesta como fenômeno, deve indicar ou expor uma cisão originária que pode ser unificada, ou uma unidade primordial que pode ser cindida"16. Assim, o fenômeno originário está no limite da intuição e da ciência, ou seja, ele é um fenômeno básico que está acima de rubricas específicas do conhecimento (quer empírico, quer científico) enquanto

\footnotetext{
${ }^{12}$ BENJAMIN, Walter. Origem do Drama Barroco Alemão. Trad. Sérgio Paulo Ruanet. São Paulo: Brasiliense, 1984. pp.67-68.

${ }^{13}$ GOETHE, J. W. Doutrina das cores, Tradução e seleção de Marco Gianotti. São Paulo: Nova Alexandria, 1993, p.60.

${ }^{14}$ GOETHE, J. W. Doutrina das cores, p.35

${ }^{15}$ GOETHE, J. W. Doutrina das cores, p.60.

${ }^{16}$ GOETHE, J. W. Doutrina das cores, p.132.
} 
saber que integra a totalidade das investigações sobre a natureza ${ }^{17}$. Dirigindo-se especialmente ao físico e ao filósofo, o poeta alemão afirma que, portando o saber do fenômeno que perpassa e se apresenta em todo particular sem a necessidade de elementos intermediários, ambos "[o físico e o filósofo] estarão, assim, no ponto máximo da empiria, de onde podem ter uma visão retrospectiva e geral de todos os graus da experiência e talvez até possam, se não adentrar, ao menos entrever o âmbito teórico"18.

Contudo, o fenômeno primordial, enquanto presença do geral no particular e oposição imanente ${ }^{19}$, não é apreendida de imediato pela linguagem, a qual sempre é refratária e não expressa diretamente objetos. Isto não significa dizer que haja uma renúncia à descrição fenomênica, mas a exigência de que se faça um uso consciente da linguagem que possa, dentre suas possibilidades, superar aspectos fenomênicos unilaterais e fornecer uma expressão ao máximo vívida dos fenômenos em suas relações mais diversas ${ }^{20}$. Enfim, os fenômenos originários não se referem somente à aparência enquanto tal, mas também à experiência a ela relacionada:

\begin{abstract}
O que integra o fenômeno se deve separar para manifestar-se fenomenicamente. O que está separado se busca de novo e pode de novo reencontrar-se e reunir-se; no sentido inferior, enquanto ele se mistura somente com seu oposto, se associa com ele, de modo que o fenômeno se torna insignificante ou, pelo menos indiferente. Mas a reunião pode ter lugar também no sentido superior, enquanto o que está separado se desenvolve gradualmente e produz mediante a conexão das partes que se desenvolveram, uma terceira coisa nova, superior, inesperada ${ }^{21}$. [Tradução do autor]
\end{abstract}

${ }_{17}$ GOETHE, J. W. Doutrina das cores, p.91.

${ }^{18}$ GOETHE, J. W. Doutrina das cores, p.130.

${ }^{19}$ Goethe compõe em torno da determinação do fenômeno cromático uma expressão imagética dessa polaridade imanente aos fenômenos em uma unidade que não pode ser efetivamente decomposta. O poeta alemão procede da seguinte maneira: "Em termos gerais, a cor pode se determinar por dois lados. Apresenta uma oposição que denominamos polaridade, que pode ser designada por mais ou menos:

+
amarelo
ação
luz
força
claro
quente
proximidade
repulsão
afinidade com ácidos

$-$

azul

privação

sombra

fraqueza

escuro

frio

distância

atração

afinidade com álcalis"

(In: GOETHE, J. W. Doutrina das cores, pp.122-123)

${ }^{20}$ GOETHE, J. W. Doutrina das cores, p. 135 e p. 130

${ }^{21} \mathrm{Na}$ tradução espanhola: "Lo que integra el fenômeno se debe separar solo para manifestarse femoménicamente. Lo que está separado se busca de nuevo y puede de nuevo reencontrarse y reunirse; en el sentido inferior, en cuanto él se mezcla sólo con su opuesto, se asocia co él, de 
Para Benjamin, em consonância com Goethe nesse procedimento triádico, a aparência não seria, como na maior parte das teorias metafísicas, o invólucro de uma essência que permanece escondida nem tampouco seria a fusão de ambas. A verdade da aparência confunde-se com o seu próprio aparecer, no desenrolar mesmo de sua própria exposição (Darstellung) ${ }^{22}$. O teor de verdade emerge pelo expediente da fixação do "sem-expressão" (Ausdrucklose) porque quebra a unidade da aparência consigo mesma e apresenta os elementos de sua constituição histórica, ou seja, os elementos transitórios. Por "sem-expressão" na obra de arte Benjamin entende aquilo que pode ser imobilizado enquanto elemento integrante da aparência: uma imagem fragmentária, um gesto, uma palavra, algum aspecto fortuito ou "irrelevante", a fim de que a própria aparência seja suspensa e que haja uma interrupção de seu movimento harmonioso - parafraseando Marx, é preciso se apropriar da matéria no detalhe. Com efeito, a fixação do "sem-expressão" permite a exposição da verdade da aparência à medida que a libera de ser "mera aparência" (blosser Schein) por meio de sua imobilização. Em um distanciamento crítico do romantismo, Benjamin situa a verdade da obra em sua particularidade exposta pela crítica de arte por meio da fixação do "sem-expressão", isto é, com base na percepção do fenômeno originário na aparência estética, a qual carrega uma oposição interna. A beleza e a verdade, longe de comporem o quadro hierárquico das ontologias tradicionais, são compreendidas necessariamente como aparência não-harmônica e imanentemente criticável.

Levando em conta o conceito de aparência constituída pela sua criticabilidade, aparência estética e crítica de arte estão intimamente relacionadas ao problema da aparência mítica no âmbito do quadro metodológico desenvolvido no

modo que el fenômeno se hace insignificante o, por lo menos, indiferente. Péro la reunión puede tener lugar también en el sentido superior, en cuanto lo que está separado se desarolla gradualmente y produce, mediante la conexión de las partes que se han desarollado, una tercera cosa nueva, superior, inesperada"(In: GOETHE, J. W. Teoría de la naturaleza. Trad. esp. Diego Sánchez Meca. Madri: Tecnos, 1997, p.177).

22 J. M. Gagnebin caracteriza a questão da auto-exposição da verdade na filosofia de Benjamin radicada no médium da linguagem para além mesmo de questões retóricas ou metodológicas, por mais relevantes que possam ser; assim, esta especificidade do pensamento filosófico ultrapassa a cisão entre sujeito e objeto, própria das filosofias da representação modernas: "A exposição não diz respeito à ordenação de elementos já acolhidos, mas ao próprio recolher e acolher desses elementos pelo pensar. Para Benjamin, portanto, não se trata somente de analisar as várias formas de exposição que pode adotar o conhecimento filosófico; mais radicalmente, trata-se de resguardar uma outra dimensão do pensamento e da escrita filosóficos: não levar a conhecimento(s), mas expor/apresentar a verdade" (In: GAGNEBIN, Jeane-Marie. Do Conceito de Darstellung em Walter Benjamin ou Verdade e Beleza, p. 186). 
projeto das Passagens. Da mesma forma Benjamin, já na obra sobre o drama barroco, diferencia o conteúdo mítico da tragédia do caráter histórico do Trauerspiel que se apresenta ambiguamente na aparência do mito, mas possui seu sentido enquanto luto lúdico que se prepara para uma vida histórica. O mito, como apresentação naturalizada da vida histórica do homem, está diametralmente oposto à história. Benjamin empreende uma crítica do mito opondo seu teor de coisa, apreendida na forma do comentário, ao teor de verdade que se traduz em dialética crítica da história, ou uma destruição dos seus elementos de naturalização ${ }^{23}$. No século XIX, os primeiros objetos produzidos na cadeia produtiva do capitalismo desenvolvido assumem significação ambígua no contexto da aparência social. Para Benjamin, esses fenômenos da cultura do fetiche da mercadoria, traduzidos na aparência mítica, são compreendidos como uma espécie de texto e possuem, portanto, uma legibilidade própria ${ }^{24}$. Conforme Benjamin, a expressão "livro do

${ }^{23}$ Cf. SAMPAIO, A. A. B. . Nos Rastros Materiais do Coletivo Onírico: Consciência Histórica e Imagem na Urgeschichte de Walter Benjamin. In: Konrad Utz; Agemir Bavaresco; Paulo Roberto Konzen. (Org.). Sujeito e Liberdade na Filosofia Moderna Alemã. 1ed. Porto Alegre: Evangraf, 2012, v. 1, p. 400-412.

${ }^{24} \mathrm{~A}$ base de aclaramento e problematização dos pressupostos metodológicos do esforço interpretativo empreendido nas Passagens encontram-se também, em estado germinal, na filosofia benjaminiana da linguagem presente no texto de juventude Sobre a linguagem em geral e sobre a linguagem humana de 1916, onde se desdobra uma teoria do nome que compreende a linguagem como mediadora da realidade em contraposição a uma função meramente instrumental ou designadora do mundo, a qual Benjamin definirá categoricamente como concepção burguesa da linguagem. No entanto, o confronto desta teoria com as teses materialistas desenvolvidas na fase madura do pensador das Passagens, as quais sugerem implicações mútuas entre gnosiologia e filosofia da história, indica a permanência do papel da linguagem como expressão e apresentação do mundo, de onde emergem os conceitos e categorias. As noções metodológicas fundamentais de imagem dialética, constelação e origem, por exemplo, exprimem sua função de apresentação e crítica fundadas no medium da linguagem. No referido texto de juventude, Benjamim parte da distinção, a ser superada, entre essência espiritual e essência lingüística que tornam possível a expressão de conteúdos espirituais comunicáveis para garantir a própria compreensão da realidade como linguagem; posteriormente, estabelece a diferença entre a linguagem das coisas e 0 ato que distingue a linguagem humana, i. é, o ato de nomear; em seguida faz menção sobre a importância da teoria do nome próprio bem como do conceito de tradução para, enfim, discutir as conseqüências da teoria lingüística fundamentada teologicamente. Portanto, esse ensaio é fundador de muitos conceitos posteriores da obra benjaminiana: a tematização da linguagem permeia todas as demais questões, pois toda realidade, seja ela animada ou inanimada, tem necessidade de apresentar pela expressão seu conteúdo espiritual. A total ausência de linguagem não pode jamais ser concebida. Na verdade, a própria realidade é linguagem, como bem exprime enfaticamente Benjamin: "Numa palavra: toda e qualquer comunicação de conteúdos é linguagem, sendo a comunicação através da palavra apenas um caso particular, subjacente a conteúdos humanos ou que nele se baseiam (justiça, poesia, etc.). Mas a existência da linguagem não se estende apenas por todos os domínios da manifestação espiritual do homem que, em qualquer sentido, contêm sempre língua, mas acaba por estender-se, pura e simplesmente, a tudo" (In: BENJAMIN, Walter. Sobre a linguagem em geral e sobre a linguagem humana in Sobre arte, técnica, linguagem e política in Sobre Arte, Técnica, Linguagem e Política. Traduções de Maria Luz Moita, Maria Amélia Cruz e Manuel Alberto; prefácio de T. W. Adorno Lisboa: Relógio d'agua, 1992, p. 177) 
mundo" indica que se pode ler o real como um texto. Assim será tratada aqui [nas Passagens], a realidade do século XIX. Nós abriremos o livro do que aconteceu" ${ }^{25}$.

Com efeito, o caráter fetiche da mercadoria, enquanto fenômeno originário das relações sociais capitalistas, possibilita uma transposição da análise da aparência enquanto categoria estética para o plano social e histórico. Na medida em que a aparência social engloba as relações de produção reificadas da sociedade burguesa apresenta-se como produto de relações sociais míticas, na aparência coisificada e ambígua dos produtos do século XIX. Donde se conclui que a resposta de Benjamin para o problema da relação entre superestrutura e base econômica não ocorre simplesmente como reflexo do desenvolvimento das forças produtivas na cultura, mas pela conexão expressiva (Ausdruckszusammenhang) de ambas as esferas da atividade humana, ou seja, do modo como os fatos econômicos estão presentes na extensão dos fenômenos visíveis.

O próprio Benjamin, em uma autoelucidação dos aspectos metodológicos do projeto das Passagens, reiterando mais uma vez uma analogia deste trabalho com livro sobre o barroco, reafirma a necessidade de apreender o desenvolvimento das formas de vida do século XIX a partir dos fatos econômicos tomados como fenômenos originários da cultura do fetiche da mercadoria e, dessa maneira, a inserção da categoria da aparência na interpretação da história:

Ao estudar, em Simmel ${ }^{26}$, a apresentação do conceito de verdade de Goethe, ficou muito claro para mim que meu conceito de origem [Ursprung]

O aspecto teológico não minimiza o caráter crítico e histórico da linguagem, os quais por sua vez não estão ancorados em uma "mística da história". A esse respeito, Benjamin também é enfático: "A palavra humana é o nome das coisas. Assim, já não pode aceitar-se a idéia correspondente à perspectiva burguesa da língua, de que a palavra se comporta de forma aleatória relativamente à coisa, de que, através de uma qualquer convenção, seria um signo oposto às coisas (ou ao conhecimento delas). A língua nunca dá meros signos. Mas é também ambígua a recusa da teoria lingüística burguesa pela teoria lingüística mística. Pois, segundo esta, a palavra é pura e simplesmente a essência da coisa. Isto é incorreto porque a coisa em si não tem palavra, é criada a partir da palavra de Deus e conhecida no seu nome segundo a palavra humana. Mas este conhecimento da coisa não é criação espontânea, não acontece a partir da linguagem de forma absolutamente ilimitada e infinita tal como a esta sucede; o nome que o homem dá as coisas assenta no modo como ela se Ihe transmite" (In: BENJAMIN, Walter. Sobre a linguagem em geral e sobre a linguagem humana, pp. 188-189).

${ }^{25}$ BENJAMIN, Walter. Passagens. Traduções de Irene Aron e Cleonice P. B. Mourão e organizado por Willi Bolle e Olgária Matos. Belo Horizonte: Editora da UFMG; São Paulo: Imprensa Oficial do Estado de SãoPaulo, 2007, [N 4, 2], p.506.

${ }^{26}$ Trata-se de um estudo de 1913, onde Simmel apresenta a estrutura filosófica do conceito de fenômeno originário, bem como o deslocamento dessa concepção para a teoria do conhecimento e da linguagem com a síntese goethiana "verdadeiramente genial" de aparência e essência. Eis como ele apresenta o conceito: "El "protofenómeno" - tal como la génesis de los colores a base de claro y oscuro, el aumento y disminución rítmicos de la fuerza de atracción de la tierra como causa de los câmbios atmosféricos, el desarollo de los organos de las plantas a partir de la forma de la hoja, el 
no livro sobre o drama barroco é uma transposição rigorosa e concludente deste conceito goetheano fundamental do domínio da natureza para aquele da história. Origem - eis o conceito de fenômeno originário transposto do contexto pagão da natureza para os contextos judaicos da história. Agora, nas Passagens, empreendo também um estudo da origem. Na verdade, persigo a origem das formas e das transformações das passagens parisienses desde seu surgimento até o seu ocaso, e a apreendo nos fatos econômicos. Estes fatos, do ponto de vista da causalidade - ou seja, como causas -, não seriam fenômenos originários; tornam-se tais apenas quando em seu próprio desenvolvimento - um termo mais adequado seria desdobramento - fazem surgir a série das formas concretas das passagens, assim como a folha, ao abrir-se, desvenda toda riqueza do mundo das plantas ${ }^{27}$.

Em suma, o trabalho sobre as galerias comerciais parisienses do século XIX constitui um desdobramento da categoria de reificação, cuja centralidade permite a inteligibilidade dos fenômenos mais variados e díspares como a moda, os reclames, o nome das ruas, o interior das moradias e os espelhos, a produção literária e até mesmo tipos sociais como o colecionador, ou seja, permite ver como os elementos mais palpáveis e concretos da aparência social cotidiana estão vinculados originariamente à constelação dos fenômenos da cultura do fetiche da mercadoria.

tipo de los vertebrados - es el caso más puro, sencillamente típico de una relación, de una, de un desarollo de la existencia natural, y por lo tanto, por una parte, una cosa distinta del fenômeno ordinario que suele mostrar esta forma fundamental en mezclas y desviaciones, pero, por outra, es precisamente fenómeno, aun cuando dado solo en visión espiritual, aunque a veces también "de algún modo presentado desnudo a los ojos del observador atento". De ordinario representamos la ley universal de las cosas como situadas de algún modo fuera de ellas: en parte objetivamente, en cuanto su validez inespacial e intemporal la hace independiente de la contingencia de su realización material en el tiempo y en el espacio, en parte subjetivamente, en cunato es asunto exclusivo del pensamiento y no se expone a nuestras energias sensibles que nunca pueden percibir más que lo particular, nunca lo universal. El concepto de "protofenómeno" quiere superar esa separación: es la ley intemporal misma en intuición temporal, lo universal que se manifiesta directamente en forma particular. Porque eso existe, puede decir Goethe: "Lo supremo sería comprender que todo lo fáctico es ya teoria. Lo azul del cielo nos revela la ley fundamental de la cromática. Que no se busque nada detrás de los fenômenos; ellos mismos son la teoria". [...] Para el uso general del lenguaje, fenômeno es aquello que existe dentro de los sentidos y mediante ellos; em consecuencia, parece completamente absurdo que el fenômeno haya de verse algo que contradiga a los sentidos" (In: SIMMEL, Georg. Goethe. Trad. esp. De José Rovira Armengol. Buenos Aires: Nova, 1949, pp. 63-65).

${ }^{27}$ BENJAMIN, Walter. Passagens, [N 2a, 4], p. 504. 


\section{REFERÊNCIAS}

\section{Obras de Benjamin}

BENJAMIN, Walter. Das Passagen-Werk, Walter Benjamin Schriften V, v1/v2. Frankfurt am Main: Surkamp Verlag, 1989.

BENJAMIN, Walter. Passagens. Traduções de Irene Aron e Cleonice P. B. Mourão e organizado por Willi Bolle e Olgária Matos. 1a ed., $1^{\text {a }}$ reimpressão. Belo Horizonte: Editora da UFMG; São Paulo: Imprensa Oficial do Estado de SãoPaulo, 2007.

BENJAMIN, Walter. Origem do Drama Barroco Alemão. Trad. Sérgio Paulo Ruanet. São Paulo: Brasiliense, 1984.

BENJAMIN, Walter. Sobre a linguagem em geral e sobre a linguagem humana in Sobre Arte, Técnica, Linguagem e Política. Traduções de Maria Luz Moita, Maria Amélia Cruz e Manuel Alberto; prefácio de T. W. Adorno Lisboa: Relógio d'agua, 1992.

BENJAMIM, Walter. Reflexões sobre a Criança, o Brinquedo e a Educação. Tradução, apresentação e notas Marcus Vinicius Mazzari; posfácio de Flávio di Giorgi. São Paulo: Duas Cidades; Editora 34, 2002.

BENJAMIM, Walter. O Conceito de Crítica de Arte no Romantismo Alemão. Tradução, prefácio e notas de Marcio Seligmann-Silva, São Paulo: Editora da Universidade de São Paulo: iluminuras, 1993.

BENJAMIN, Walter. Ensaios reunidos: escritos sobre Goethe. Trad. de Mônica Krausz Bornebusch, Irene Aron e Sidney Camargo. São Paulo: Duas Cidades; Ed. 34, 2009.

BENJAMIN, Walter. La Metafísica de la juventud. Trad. esp. de Luis Martínez de Velasco. Barcelona: Paidós Ibérica, 1993.

\section{Obras de outros autores}

AGAMBEN, Giorgio. "Langue e histoire: Catégories historiques et catégories linguistiques dans la pensée de Benjamin" In WISMANN, Heinz. (organizador). Walter Benjamin et Paris, pp.793-807. Paris: Les èdition du Cerf, 1986.

BUCK-MORSS, Susan. Dialética do olhar: Walter Benjamin e o projeto das Passagens. Tradução de Ana Luiza Andrade. Belo Horizonte: UFMG; Chapecó: Argos, 2002.

CASTRO, Cláudia. A Alquimia da crítica: Benjamin e as afinidades eletivas de Goethe. Rio de Janeiro: Paz e Terra, 2011.

COUTO, Edvaldo Souza; DAMIÃO, Carla Milani (Organizadores). Walter Benjamin, Formas de percepção de estética da modernidade. $1^{\underline{a}}$ Ed., Salvador: Quarteto, 2008. 
GAGNEBIN, Jeane-Marie. Do Conceito de Darstellung em Walter Benjamin ou Verdade e Beleza. In: Kriterion vol.46 no 112 Belo Horizonte Dec. 2005.

GALE, Pedro Fernandes. Em torno do olhar - a formação do método morfológico em Goethe. [dissertação de mestrado] USP: 2009

GILLOCH, Graene. Walter Benjamin. Trad. it. Stefano Manfredi. Bologna: il Mulino, 2008,

GOETHE, J. W. Doutrina das cores. Trad. br. Marco Giannotti. São Paulo: Nova Alexandria, 1993.

GOETHE, J. W. Teoría de la naturaleza. Trad. esp. Diego Sánchez Meca. Madri: Tecnos, 1997.

MACHADO, Francisco de Ambrosis Pinheiro. Imanência e História: a crítica do conhecimento em Walter Benjamin. Belo Horizonte: editora UFMG, 2004.

SAMPAIO, A. A. B. . Nos Rastros Materiais do Coletivo Onírico: Consciência Histórica e Imagem na Urgeschichte de Walter Benjamin. In: Konrad Utz; Agemir Bavaresco; Paulo Roberto Konzen. (Org.). Sujeito e Liberdade na Filosofia Moderna Alemã. 1ed. Porto Alegre: Evangraf, 2012, v. 1, p. 400-412.

SIMMEL, Georg. Goethe. Trad. esp. de José Rovira Armengol. Buenos Aires: Nova, 1949.

STEINER, Uwe. "Zarte Empirie: Überlegungen zum Verhältnis von Ursprung in Frühund Spätwerk Walter Benjanins", pp. 20-40 in: BLOZ, Nobert W.; FABER, Richard (organizadores) Antike und moderne: zu Walter Benjanins Passagen. Würzburg: Königshausen und Neumann, 1986.

TIEDEMANN, Rolf. Études sur la philosophie de Walter Benjamin. Trad. de Reiner Rochlitz. Actes Sud, 1987. 